\title{
Methodical bases for forming the structure of management of innovative activity of large building holdings
}

\author{
Evgeniya Sizova ${ }^{1, *}$, Evgeniya Zhutaeva ${ }^{1}$, Roman Gorshkov ${ }^{2}$, Vitaly Smirnov ${ }^{3}$, and Elena \\ Kochetkova ${ }^{4}$ \\ ${ }^{1}$ Voronezh State Technical University, Moscow Avenue, 14, 394026, Voronezh, Russia \\ ${ }^{2}$ Moscow State University of Civil Engineering, Yaroslavskoe sh., 26, 129337, Moscow, Russia \\ ${ }^{3}$ Moscow Aviation Institute, Volokolamskoe highway, 4, Moscow, 125993, Russia \\ ${ }^{4}$ Moscow state University of technology and management. K. G. Razumovsky, Zemlyanoy Val street, \\ 73, Moscow, 109004, Russia
}

\begin{abstract}
The article considers the features of innovative activity from the standpoint of ensuring sustainable development of the construction industry, presents the features of construction that determine the objective need for innovation and the reasons for the industry's inertia towards innovations that hamper the process of transition to an innovative development path. The role of large enterprises as participants in the implementation of investment projects contributing to their most effective implementation is considered. The features of the management structure of innovation activity are justified. The factors determining the innovative management structure in holdings, considered possible variants of administrative interaction depending on the process involved in the control subjects and their functions.
\end{abstract}

\section{Introduction}

Innovative activity as an activity connected with the use of research results for the development of new products or technology and their further commercialization should combine both a rational scientific organization of fundamental and applied research and an orientation towards the most effective feasibility in real economic conditions. The fulfillment of these requirements is the basis of innovative activity, based on the ability of the business unit to develop on its own in the future, which is one of the most important factors for ensuring sustainable development.

The issues of innovation management were considered in the works [1-4].They noted that innovation activity is characterized by a high level of risk, significant expenditure of financial and other resources, as well as complexity and duration, which requires simultaneous and mutually agreed participation in the implementation of innovative projects of a significant number of entities. Researchers repeatedly attempted to analyze separate groups of participants in innovation activities and their characteristics. Issues of

*Corresponding author: sizova@vgasu.vrn.ru 
classification of subjects of innovation activity were considered in the works [5-7]. Among the common shortcomings of the proposed classifications can be identified an excessive level of detail, based on the insignificant differentiation of subjects, and, conversely, too large-scale consideration of subjects that do not allow to obtain sufficiently accurate and reliable results.

Questions specific to large enterprises as a participant in economic relations are reflected in the works [8-10]. Among the features of large enterprises that allow them to act as one of the most important market players, they emphasize stability under the influence of destructive factors of the external environment, extensive opportunities for diversification of activities, preferences in attracting funds from the state and credit institutions, the effect of scale of production and a significant concentration of material, labor and other resources. However, the issues of the operation of large enterprises in the innovation environment, their role and the mechanisms of innovation have not been adequately reflected in scientific research. In addition, it is important to consider directly the processes of forming the structure of innovation management in large business associations. This structure is further complicated by the fact that the holding is a set of economic units characterized by considerable independence and, at the same time, acting as a single entity.

\section{Materials and methods}

Strategic and tactical management of innovation activity allows solving a number of tasks aimed at increasing the effectiveness and effectiveness of innovations in the organization. At the same time, the range of tasks to be solved is largely determined by the branch specificity of the business entity. Therefore, the process of analyzing the mechanisms for the formation of the management structure of the innovative activity of holdings in construction precedes the identification of its characteristics, which will also determine the composition of the participants and the nature of the relationship between them, sources and procedure for financing, management methods and a number of other characteristics.

The need for innovation in the construction industry is caused by the growing need to improve construction projects. From year to year, the objects are subjected to increasingly high demands of durability and stability under the influence of environmental factors, which directly depend on the properties of building materials and the features of the technologies used. In addition, modern business conditions imply a constant increase in the reliability of facilities and their operational safety. Therefore, construction organizations need to focus on scientific developments aimed at improving the characteristics of construction projects and increasing the progressiveness of construction processes (Fig. 1). 


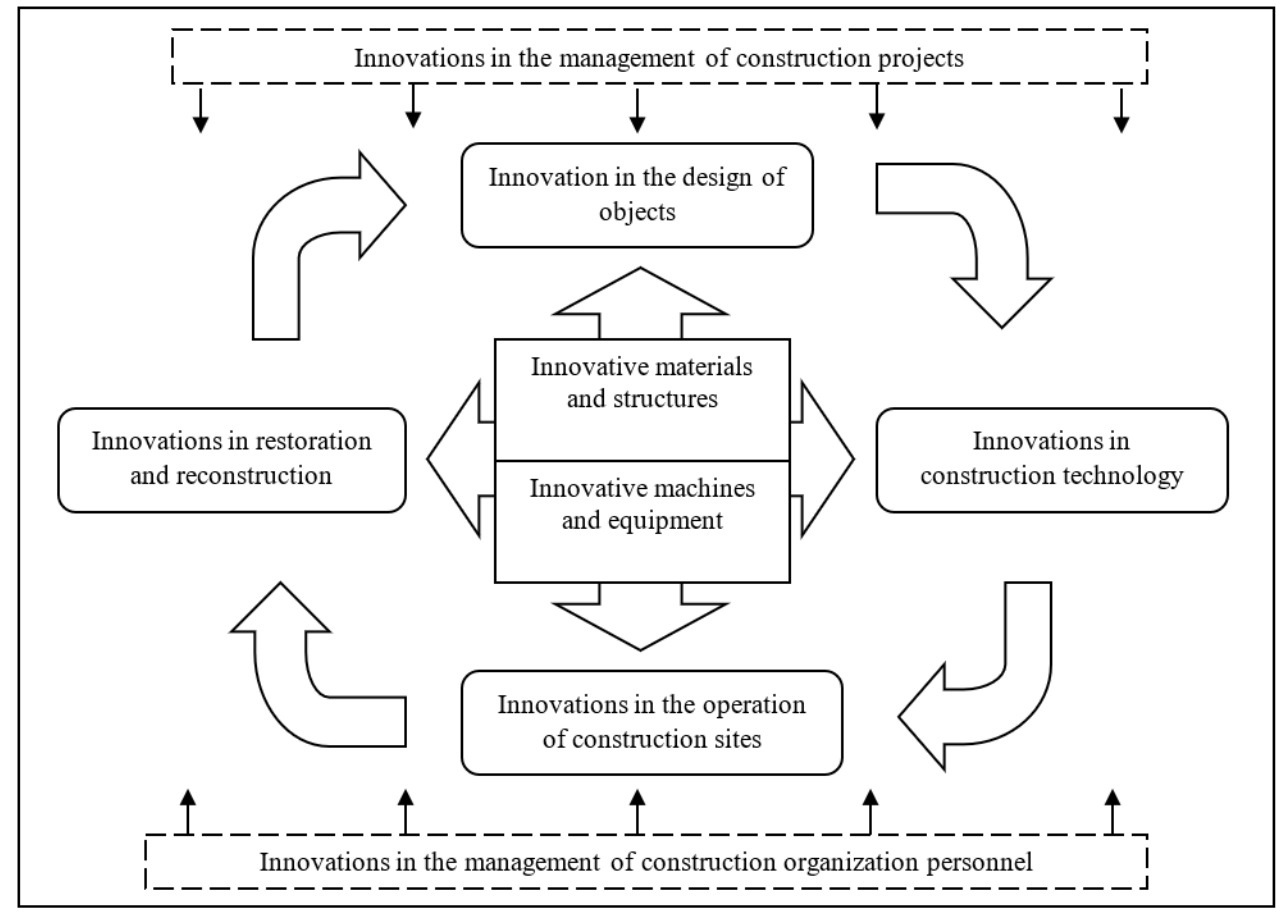

Fig. 1. Directions of innovative activity in construction.

Of particular importance at the present time in accordance with the concept of sustainable development is the solution of problems of harmful impact on the environment in the face of limited resources. Construction is one of the most resource-intensive industries, so the use of innovative resource-saving technologies will achieve a significant positive effect. Particular attention is currently paid to "green" innovative technologies, projects related to the secondary use of raw materials, energy-saving technologies and developments that allow to cause minimal damage to the environment.

However, despite the listed features, construction companies are characterized by a high degree of conservatism in the introduction of innovations. Low innovative activity in construction is often explained by the duration of the production and operational cycle of construction projects, which cause a significant time gap between the implementation of development costs and the receipt of the effect of innovation. The unfavorable situation with the susceptibility to innovations is to a large extent predetermined by the low innovative readiness of managers and employees and the insufficient effectiveness of the management system.

The largest potential for meeting the requirements set by innovation, given its complexity, multi-stage and high-risk, have large holding structures. Creation of holding structures means the formation of powerful systems capable of forming the basic modern elements of a market economy. Because of this, the leading task of holding structures is the integration into a single process of all stages from research, design, development work to the implementation and commercialization of results [9].

\section{Results}


Rational organization of innovation management at the enterprise is the foundation that ensures the efficiency and effectiveness of innovative processes. Among the requirements for the organizational structure of innovation management, the following:

1. A high level of adaptability to the changing factors of the external and internal environment, the ability to adapt to organizational changes caused, inter alia, by previous results of innovation;

2. Orientation to the application of advanced world achievements in the field of innovation management;

3. Correspondence of the mission, strategy, goals and objectives of the business entity, the specific stage of its life cycle, the sectoral order of development and implementation of innovations;

4. Creation of conditions for the most rational division and cooperation of labor between subdivisions and individual executors, a clear specialization of the work carried out;

5. Formation of the system of personnel support of innovative activity (training and retraining of personnel, a system of motivation, etc.), forming labor potential and contributing to more efficient work with innovations;

6. Providing the opportunity to accumulate knowledge and experience in each of the areas of innovation [11].

Proceeding from the above requirements and specific features of large holdings, it follows that the formation of structures (bodies, links, actors) participating in the innovation activity of the holding can take place in various forms, the main of which are the creation, absorption, spin-off and market innovation integration (Fig. 2).
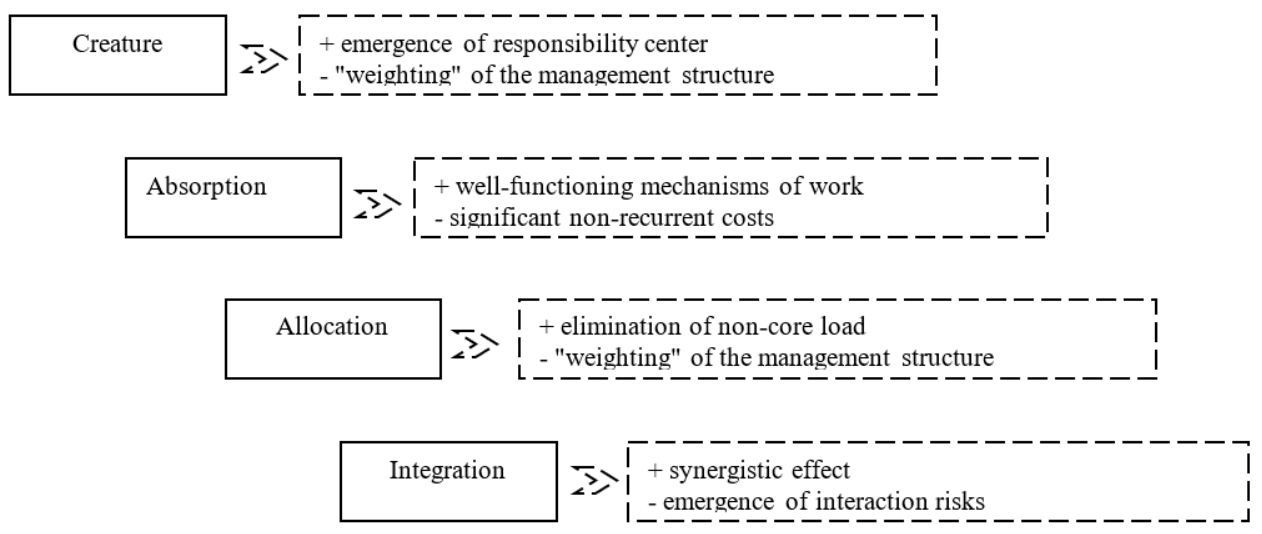

Fig. 2. Forms of creation of innovative structures of large enterprises.

The management structures of innovation activity determine the interaction of managing and managed entities through horizontal and vertical links. The structure is characterized by a wide variety of forms of interaction between scientific and industrial enterprises and divisions [12].

The uniqueness of each business entity generates individual characteristics, which are a combination of advantages and disadvantages. Such features can be formed under the influence of events, managerial decisions, factors manifested in the process of interaction with other actors, resulting from the nature of the innovations being implemented and previous experience of their implementation, the availability of partnerships with external innovation enterprises, as well as the existing corporate innovation culture. All this must be taken into account when forming an innovation management structure. The key internal 
factors and conditions that determine the structure of management of the holding's innovative activity can be conditionally divided into two groups (Fig. 3).

Comprehensive and thorough analysis of information on the presented directions will contribute not only to the formation of the optimal management structure that best meets the requirements of the given business association, but also the adoption of effective management decisions, the formation of an innovative strategy and the selection of participants in the innovation network, based on strong and weak points, which will help avoid "problematic" areas or develop measures for their elimination.

Allocation of a specialized unit within the holding company that carries out strategic and operational management of innovative development makes it possible to clearly delineate the functional, formulate a set of goals and tasks, and concentrate information and labor resources in one business unit, resulting in an increase in the efficiency of their use in the innovation process. The presence of an innovation center implies a high level of qualification of its employees in the field of innovations, since it requires taking into account the differentiation of the constituent entities and their innovative needs. In addition, this structure requires the presence of developed channels of communication and organizational sensitivity of the constituent entities to centralized management.

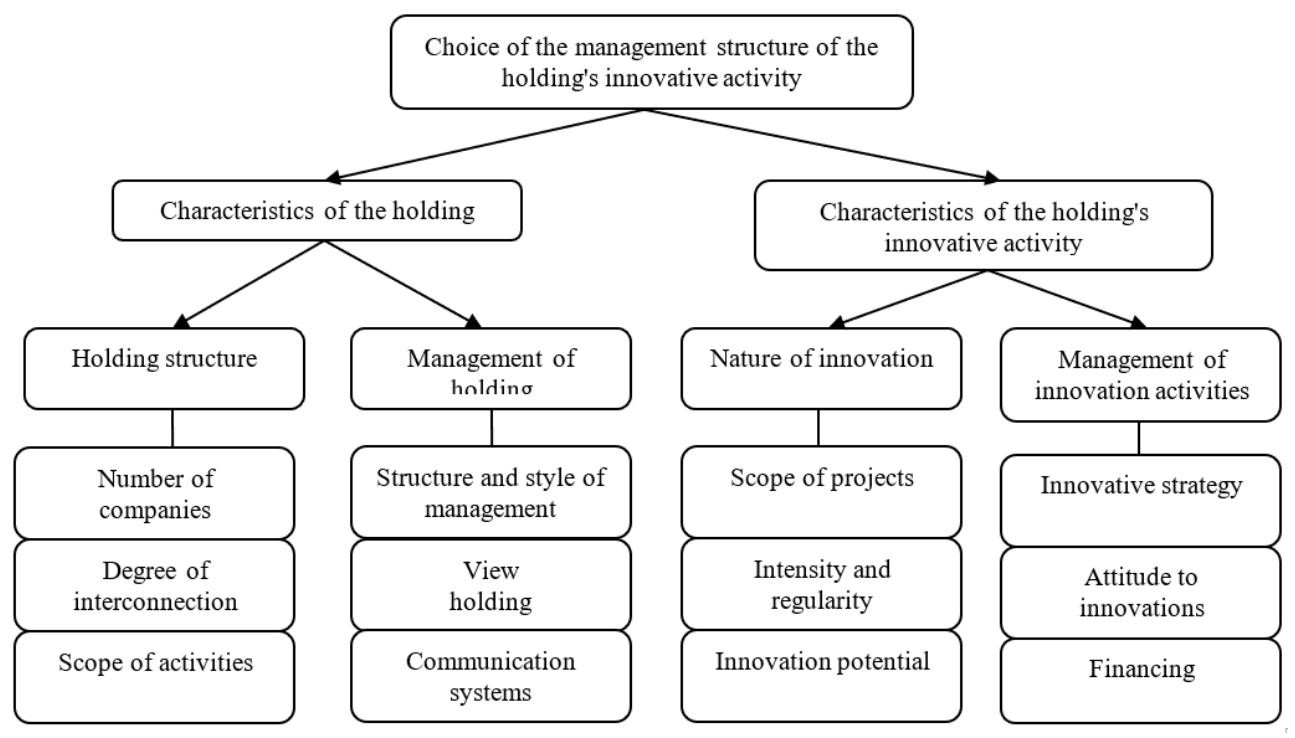

Fig. 3. Scheme of factors influencing the organizational structure of management of innovative activities of the holding.

Adherence to a decentralized management structure does not mean the absence of a business unit responsible for innovation. As part of the holding there is also a single innovation center, but behind it are consolidated only the general management functions, which consist in the formation of priority technological directions for development, the implementation of technological modernization and the formation of the innovative infrastructure of the holding. In turn, the formation and implementation of innovative strategies are conducted by the holding's subsidiaries. Thus, they are given a significant share of autonomy, which can positively affect the innovation activity due to the proximity to sources of innovative needs. This allows the subsidiaries to form their own innovative program that best meets their requirements. This type is also typical for holdings that are at the initial stages of development, when the subject managing innovations is forced to combine innovation management activities and a number of other areas. 
It is also possible to transfer functions related to innovation management to a specialized third-party organization. This method helps to reduce the risk by using the outsourcer accumulated knowledge base, unique equipment, highly qualified personnel, while the volume and direction of the transferred functions can vary. Thus, the holding gets an opportunity to focus management efforts only on those areas of innovation that do not need to increase efficiency or have a particular strategic value.

\section{Discussions}

The transition to the innovative development of building holdings should be carried out by gradually introducing innovative activities into business practices and creating the necessary conditions for its successful implementation. First of all, this requires the use of modern information technologies, systems for processing and analyzing information on existing or proposed projects, knowledge, methods and models, innovative solutions of world level. It is the formation of a large-scale base of accumulated knowledge, oriented to the advanced achievements of engineering and technology in the field of construction, and an effective communication system within the integrated structure and with the subjects of the external environment, that will allow using the intellectual potential of the holding and enhance the innovative readiness. Equally important will be the system of training and retraining of specialists to ensure professional activity in both management and organization, and in the field of generation and introduction of innovations directly into production. To ensure a sufficient level of security, it is necessary to activate mechanisms for the legal protection of results at all stages of the innovation process. This will prevent the possible receipt by competitors of the benefits from the results of innovation without the implementation of the corresponding costs for the development and implementation of innovation.

\section{Conclusion}

Construction is an industry in which innovations can be implemented in a significant number of areas, but participants in the construction industry are often characterized by a low level of innovative activity. To date, the specifics of innovation is determined not only by industry aspects, but also by the scale of the activity. Based on the capital intensity and the need to overcome barriers, the most preferred participants in the business sector are large enterprises that have an optimal, well-designed and coordinated mechanism for managing and selecting projects, taking into account the specifics of large enterprises. The potential of large holdings creates conditions for the introduction of processes for the implementation of innovations in business management. However, the management of innovation is characterized by complexity that does not involve the use of "template" methods and methods. At the same time, management structures are characterized by the degree of centralization and directivity, the direction of the flows arising in the course of innovation activity, and the nature of the interaction between the divisions and subsidiaries. The choice of the structure of innovation management in the holding will have a significant impact on the efficiency and effectiveness of innovation activities.

\section{References}

1. K. Gumba, S. Belyaeva, IOP Conference Series: Earth and Environmental Science 90(1), 012163 (2017) 
2. A. Bukreev, O. Vasilyeva, V. Vlasenko, E. Sizova, MATEC Web of Conferences, 106 (2017)

3. S. Uvarova, S. Belyaeva, L. Myshovskaya, IOP Conference Series: Earth and Environmental Science 90(1), 012169 (2017)

4. K. Gumba, S. Uvarova, S. Belyaeva, S. Revunova, MATEC Web of Conferences 106, 08023 (2017)

5. K. Zhiharev, Russian economic online magazine 2, 33-45 (2011)

6. E. Sizova, E. Zhutaeva A. Chugunov, MATEC Web of Conferences 33, 03016 (2018)

7. S. Belyaeva, D. Voronov, S. Erypalov, MATEC Web of Conferences 106, 08033 (2017)

8. M. Kuvaldin, Bulletin of Kazan Technological University 1, 184-186 (2012)

9. A. Alexandrova, Problems of Modern Economy 3(47), 62-65 (2013)

10. A. Bryakina, Territory of Science 3, 5-11 (2012)

11. A. Kuryatnikov, N. Linder, Business Strategy 8(16), 16-24 (2015)

12. O. Anisimova, Theoretical and Practical Aspects of Economics and Intellectual Property 1(3), 283-286 (2013) 